\title{
Téoros
}

Revue de recherche en tourisme

\section{Fêtes, événements et... culture pour touristes}

\section{Marc Laplante}

Volume 5, numéro 2, juillet 1986

Tourisme, fêtes et événements

URI : https://id.erudit.org/iderudit/1080570ar

DOI : https://doi.org/10.7202/1080570ar

Aller au sommaire du numéro

Éditeur(s)

Université du Québec à Montréal

ISSN

0712-8657 (imprimé)

1923-2705 (numérique)

Découvrir la revue

Citer cet article

Laplante, M. (1986). Fêtes, événements et... culture pour touristes. Téoros, 5(2),

7-8. https://doi.org/10.7202/1080570ar d'utilisation que vous pouvez consulter en ligne.

https://apropos.erudit.org/fr/usagers/politique-dutilisation/ 


\title{
Fêtes, événements et... culture pour touristes
}

\author{
par Marc Laplante*
}

Fêtes et tourisme ont de nombreux points communs que l'anthropologie a su décou. vrir (voir l'article de Bernard Arcand dans le présent numéro). La méme discipline a cependant révélé plusieurs tensions entre ces deux réalités culturelles.

Pour maximiser ses chances de réussite, l'organisation touristique n'a pas hésité parfois à fabriquer de toute pièce la fête touristique ou la vacance festive dont le Club Med, par sa publicité du moins, reste l'exemple le plus connu.

Ces produits touristiques nouveau genre ont pris des formes diverses au cours du dernier quart de siècle du développement du tourisme. Deux de ces formes nous intéresseront ici particulièrement à cause de leur importance au Québec: a) la récupération de la fête par le tourisme et b) l'introduction d'événements-prétextes pour attirer les touristes.

\section{La fête récupérée}

Un cas exemplaire de récupération de la fête par le tourisme est celui de l'Alarde, une cérémonie publique commémorative qui a lieu à Fuenterrabia en pays basque espagnol. Greenwood ${ }^{(1)}$ a décrit ce phénomène que nous résumons d'abord brièvement.

Qui en tourisme ne connait pas la demande universelle des visiteurs pour la couleur locale? La francité mẻme est présentée avec l'image de Montréal comme une couleur locale (Skiez a la française). Les cultures locales. du point de vue de l'anthropologie, forment des systèmes intégrés de significations par lesquels la nature du réel est établie et maintenue. Les expériences de vie du groupe y trouvent leur authenticité et leur sens moral. Ces expériences partagées par une communauté s'expriment par des rituels publics à l'occasion desquels sont réaffirmés, commentés, élaborés ces faits qui unissent un groupe de gens dans une commune culture. La procession de la Saint-Jean Baptiste au Québec, avant sa remise en question à partir de 1967, pou-

\footnotetext{
"Mare Laplante est sociologue en professeur en tou. risme, rattache au departement d'etudes urbaines da IUDAM.
}

vait être considéréte comme un de ces rituels publics.

L'Alarde de Fuenterrabia était un de ces rituels par excellence; il recréait la victoire de cette ville contre les Français après le siège de 1638 . La cité, située presque à la frontière qui sépare 1'Espagne de la France en pays basque, fut assiégée de nombreuses fois lors des luttes territoriales entre les deux pays. Le siège de 1638 fut le plus célèbre et chassa les Français pour longtemps. Fuenterrabia fut récompensée pour cette victoire qui lui valu plusieurs privilèges.

Depuis cette date mémorable jusque vers 1970 , le cérémonial de l'Alarde fut repris, d'année en annéc, avec tous les citoyens de la ville, s'enrichissant toujours de symbolisme. La cérémonie est centrée sur la notion de solidarité, d'union de tous contre l'ennemi commun. Cette solidarité a assuré la victoire en 1638 et est recréée ensuite par la fété.

Haute en couleur, par ses processions, ses costumes, ses gestes symboliques, l'Alarde est organisée pour souligner le lien entre toutes les classes sociales de la ville, tous les groupes d'äge et de sexe, etc... La vie quotidienne à Fuenterrabia est comme partout ailleurs, avec ses clans, ses groupes, ses tensions sociales; mais pour un jour, la fête efface ces différences: du maire jusqu"aux matelots des quais, chacun a un róle.

Le clou de l'évênement est l'arrivée sur la petite place centrale de la ville de corps de garde venant de chaque quaj et de chaque quartier. En arrivant sur la place, le corps tire un coup de feu en recherchant l'unisson la plus parfaite possible. Le reste de la ville, déjà sur place, commente ces essais de tir à l'unisson. (l'idéal: cents tireurs ne tirant que comme un seul). $\hat{\mathrm{A}}$ la fin, quand tous les corps sont sur la place, ils tirent encore ensemble en tentant la mème unanimité

On comprendra très vite le sens de ces exercices qui alimentent toutes les discussions du reste de la joumée: la solidarité mémorable est reconstituée par l'habileté de cen- taines de fusils tirant ensemble. On comprendra aussi que les habitants de Fuenterrabia font cente cếrémonie pour eux: c'est une féte participative car chacun y tient un rôle, même les très jeunes enfants. Traditionnellement, seuls quelques dignitaires de la région se joignaient à ceux de la ville sur le balcon d'honneur surplombant la grande place.

Mais l'Alarde se fête en pleine saison touristique. La ville est for achalandéte aujourd "hui; les guides touristiques ont inscrit l'Alarde parmi les attractions: vers 1965 , les édifices d'une des façades de la grande place (qui n'est pas très gande en mètres carrés et qu'on ne trouve qu'après avoir suivi des rues très étroites) sont devenus un parador (une hôtellerie gouvernementale typique d'Espagne).

Il arrive que des spectateurs voulurent assister à la cérémonie mais la participation de l'ensemble de la ville laissait peu de place à ces visiteurs étrangers. En 1969, devant la pression touristique et suite à l'ouverture du parador, devant les pressions du ministère du Tourisme, les autorités municipales annoncèrent que l'Alarde devrait être donnée deux fois le même jour pour que de plus en plus de touristes puissent $y$ assister.

Du coup, un grand moment de la culture locale devenait un show (désigné pudiquement par le terme de service culturel, ce qui en fait quand méme un bien de consommation que le marketing de service sait commercialiser).

Grand malaise dans tout Fuenterrabia, consternation méme parmi plusieurs groupes participants, puis rupture du symbolisme de la solidarité car certains groupes ont prêté à d'autres des intentions de vouloir faire des sous avec l'histoire locale, etc.

En fait, il semble que l'Alarde ne fut jamais donnée deux fois le même jour. En post face de son texte, Greenwood mentionne qu'en 1976, la fété fut un événement politique avant tout, que des affrontements eurent lieu sur les quais avec la police (comme pour notre St-Jean) entrainant la 
mort d'un travailleur d'une cité avoisinante.

Une toute petite manoeuvre touristique venait de déclencher un processus irréversible de déplacement de sacralisation. Evénement réellement sacré (bien que laique) pour les gens de Fuenterrabia, $l^{\prime}$ Alarde, devenue une attraction, un spectacle pour les touristes, ne pouvait plus mobiliser toute une ville autour du theme de la solidarité. Si elle survit comme attrac. tion touristique, c'est gràce à la publicité et à une organisation de spectacles qui s'en charge chaque année.

Dans ce cas précis, les habitants de Fuenterrabia ont été dépossédés d'une partie de leur culture et appauvris sans compensation. Leur situation differe radicalement de celle d'un groupe de musiciens ou d'acteurs qu'on paie en échange de services culturels destinés aux touristes (cas des festivals d'été de théâtre, de musique, etc...).

L'analyse du cas de l'Alarde pourrait-elle servir à interroger certaines de nos fêtes québécoises? Chez nous, l'essentiel des rituels collectifs fut lie à la religion (la procession de la Fête-Dieu, reconstituée dans les Plouffe, en donne une idée). Le déclin de ces cérémonies a peu à voir avec le tourisme.

Mais il faudra d'abord faire avancer l'étude des fètes dans notre propre milieu avant de conclure que des récupérations comme celle de Fuenterrabia n'ont pas eu lieu. Et l'enseignement à tirer de cet exemple peut servir aux futurs touristes et à leurs obsessions pour la couleur locale.

\section{La montée des événements-prétextes}

Si le tourisme peut faire perdre son sens profond aux manifestations de culture locale les plus enracinées. il est capable aussi de bien d'autres tours d'illusionnistes.

Quand les gens de Chicoutimi partent à la recherche de leur passé à l'occasion d'un Carnaval qui regroupe très souvent les membres des grandes familles éparpillées sur tout le territoire du Québec, cet événement annuel $s^{\dagger}$ inscrit sans hésitation comme une manifestion de culture locale (même si la publicité est à l'oeuvre pour en faire un événement touristique). On peut $y$ voir des Québécois cherchant à préserver, à actualiser, à recréer leur identité. L'intelligence des concepteurs de cet événement fut d'adopter la forme du Carnaval qui favorise l'insertion temporaire des étrangers dans la fête.

Il en va tout autrement du Festival western de St-Tite, sorte de campagne publicitaire de marchands de bottes de cuir. La culture western, fait certain de civilisation dans l'Ouest américain et canadien, $\mathrm{n}$ 'a donné au Québec que des chanteurs-imitateurs

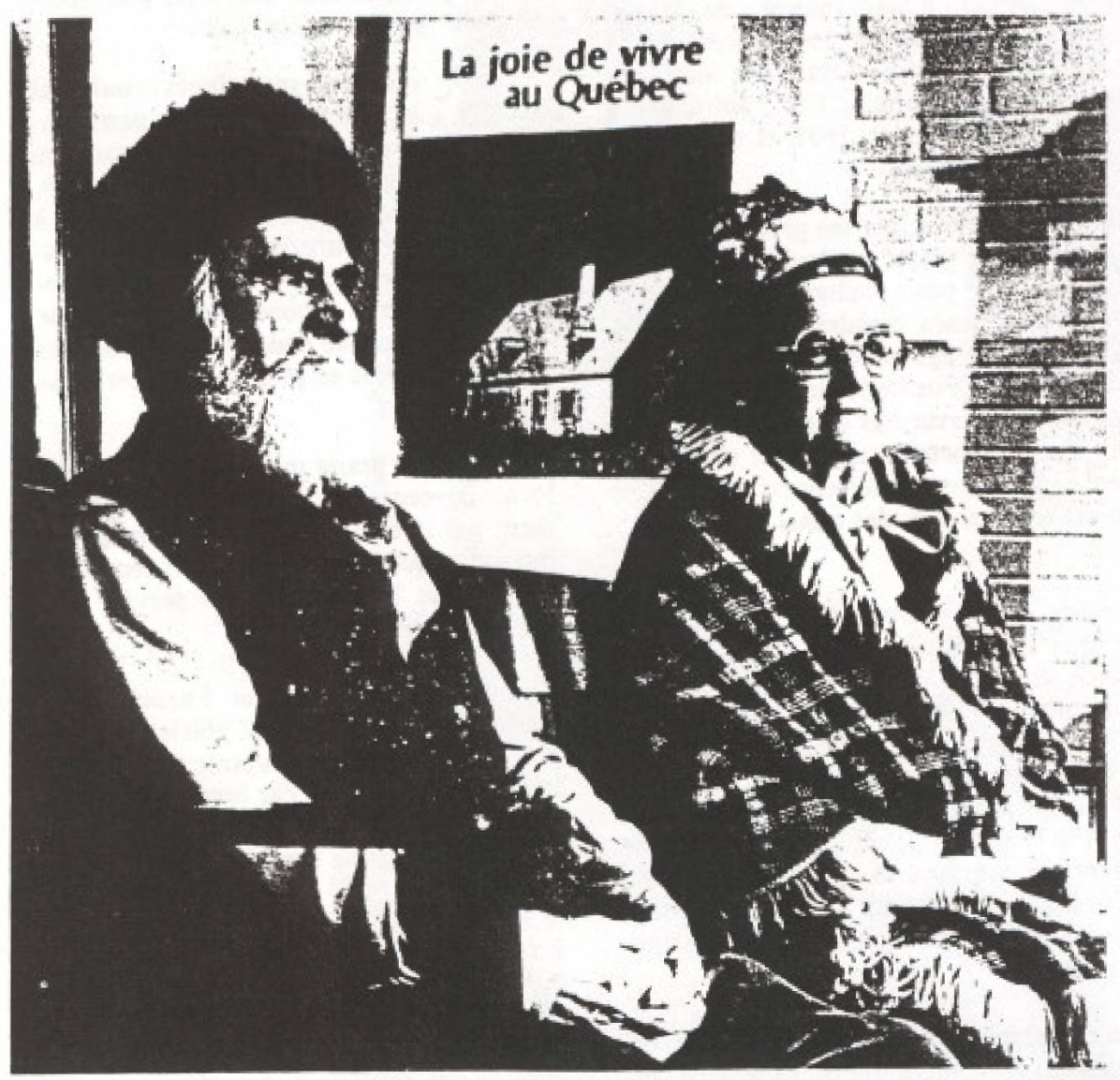

Des Qud́bócois cherchant à préserver, à actualiser. à recréer leur identité...

Evocation de l'année 1978 au Carnaval-Souvenir de Chicoutimi.

d'un genre à succès né ailleurs. On trouverait difficilement d'autres traces et surtout quelques expressions québecoises particulières de cette culture dans notre histoire. Il en serait tout autrement si un festivcal était consacré aux coureurs des bois ou encore, aux draveurs dont lé seul personnage de Menaud par Félix-Antoine Savard pourrait constituer tout un programme. St-Tite n'est qu“un prếtexte pour attirer des touristes, comme un village du Père Noêl au Vermont:

Prétexte aussi, peut-être, certains événements prestigieux comme récemment à Montréal l'exposition sur Ramsès II, la collection des Picasso ou les Trésors de Chine. Certes, beaucoup de Montréalais et de Québécois en profitent comme ils le font d'autres expositions et événements culturels (jazz, théátre, mimes, marionnettes, cinéma, feux d'artifice, etc.). Mais les événements mentionnés ci-haut, et aussi ceux du Grand Prix, du Tennis et metme des Jeux Olympiques ont une intention nettement touristique compte tenu des efforts de promotion et de publicité qui les accompagnent.

A plus long terme, ce filon ne risque-t-il pas de s'épuiser? Surtout, 100 événements comme Picasso ou Ramsès II au Québec finiront-ils par révéler aux visiteurs étrangers quelque chose de nous-mèmes en tant que société et culture originales?

Une journée à Dysneyworld ou à Cap Canavéral nous met en présence de deux manifestations fortes de la culture américaine; quelques jours au Rodéo de Calgary nous racontent 100 ans d'histoire régionale; deux jours dans la vallée de la Loire, avec ses chăteaux et ses sons et lumières nous font revivre de grands moments de I'histoire de France; une journée à Montréal pour découvrir les trésors chinois nous révèle... la Chine ancienne!

\section{Conclusion}

Fètes, évếnements et tourisme ne forment pas toujours le meilleur des cocktails. La représentation culturelle à des fins touristiques relève d'un art nouveau qui attend encore son premier génie. Devant la difficulté d'inventer nos représentations pour nous raconter et nous révéler aux visiteurs, la tentation est grande de se replier sur du tout cuir: une fête ancienne servie à la moderne, ressuscitée pour charmer les touristes ou encore, l'emprunt de pièces impressionnantes - déjà tout auréolées de prestige- dans la culture des autres. $f$

\footnotetext{
Reforences

[1] GREENWOOD, D.J. Culture by the Pound: An Anthropological Perspective on Tourism as Culpural Commoditization, in SMITH, V.L. led.) Host and Guests: The Anthropology of Tourism. University of Pennsylvania Press, 1977, chapitre 8
} 